\title{
A new species of Miogryllus Saussure, 1877 from Andean Venezuela with bizarre cephalic morphology (Orthoptera, Gryllidae, Gryllinae, Modicogryllini)
}

\author{
FRANCISCO DE A. G. DE MELLO \& JOÃO PAULO MORSELLI \\ Departamento de Zoologia, Instituto de Biociências, São Paulo State University (UNESP), 18618-970 Botucatu, São Paulo, Brazil. \\ E-mail: framello@ibb.unesp.br
}

\begin{abstract}
Miogryllus muranyi n. sp. is described from the Andean Acacia-Cactaceae semi-desert bush in the Chama Valley of Venezuela. The species is characterized by the unusual shape of the male head, which makes it readily distinguishable from any other congener known to date.
\end{abstract}

Key words: Orthoptera, Grylloidea, Miogryllus, South America, Andes, description, taxonomy

\section{Introduction}

The genus Miogryllus Saussure, 1877 presently comprises eleven species occuring from United States to southern South America.

Hebard (1915) revised Miogryllus and mentioned the occurrence of a megacephalic condition "in ocasional individuals, particularly of the male sex" with reference to the group Gryllites. He also noted the presence of micropterous individuals (i.e., specimens in which the metathoraxic wing is as long as or shorter than the mesothoraxic one) and macropterus ones (those in which the hind wing is decidedly longer than the fore wing) in $M$. convolutus (Johannson 1763). In males of M. lineatus (S. H. Scudder 1876), a megacephalic condition is occasionally found in males, as well as the presence of micropterous and macropterous individuals of either sex. Micro and macroptery, as well as micro and megacephaly, was also reported from M. verticalis (Serville 1838).

Our experience with Miogryllus suggests that its species are not at all associated with wet, dense-canopied, shady forests. Rather, all putative species present in the local collection have come from open formations like the cerrado and caatinga vegetations of Brazil, coffee, sugar-cane and other crops, as well as from Pinus or Eucalyptus reforestments.

Here we describe a new species of Miogryllus from the Andean Acacia and Cactaceae semi-desert bush in the Chama Valley of Venezuela in which the male has an odd head morphology, very different from those of any other congener described so far.

The nomenclature we employ for the phallic structures follows the proposal of Desutter (1990) with the changes she suggested more recently (Desutter-Grandcolas 2003).

\section{Miogryllus Saussure, 1877}

Definition. 1-male fore wings abbreviated, leaving a large portion of the abdomen uncovered; 2 -female fore wings as long as or shorter than pronotum, its dorsal field sub-triangular, the internal margins not touching each other; 3-dorsal face of pseudepiphallus with a broad U-shaped invagination that leaves the apex of the ectophallic fold uncovered; 4-rami not fused anteriorly. 